\title{
COHERENCE AND COHESION، AN ANALYSIS OF THE FINAL PROJECT ABSTRACTS OF THE UNDERGRADUATE STUDENTS OF pGRI semarang
}

\author{
Suwandi \\ University of PGRI Semarang \\ drsuwandi2@yahoo.com
}

Article received: 10 May 2015

Final proof received: 21 Januari 2016

\begin{abstract}
An abstract is the gist of a research report which has the purpose to allow the reader to get the main information without reading the whole document. Since it plays an important role in grasping the information of the whole research report, the writing of the abstract, therefore should be concise and the logical relation among sentences is clear, coherent and cohesive. However, many of the students still find difficulties in making their writing coherent due to their limitation in understanding the cohesive devices and their application in their writing. This article attempts to reveal the coherence of the abstracts of the final project reports of the undergraduate students of PGRI University Semarang, Indonesia. Its objectives are (1) to reveal the micro-level coherence, how each sentence is connected to the other to make logical relations and (2) to discover the macro-level coherence, the right use of cohesive devices like conjunction, reference, substitution or ellipsis so as to make the whole text coherent. Several abstracts of the students' final projects were selected randomly to be analyzed. Since it is a qualitative research, the data were in the level of words or sentences. The result shows that the abstracts analyzed have not satisfactorily achieved coherence though some cohesive devices like reference, conjunctions, ellipsis which are used to link one sentence to the other. Some grammatical mistakes are also found such as the plural forms, active-passive voice.
\end{abstract}

Keywords: abstract, coherence, cohesion, final project report

The ability to write a text has played an important role for the undergraduate students of the English Department in Indonesia since it is one of the requirements to graduate from the university by submitting their final project reports written in English. Not only important to fulfill the requirement of the university graduation, the ability to write well is actually very essential and very much required for their further studies. In postgraduate program, for example, students are always assigned to write papers to be presented in the lecture session so as to be able to develop their knowledge. Therefore, as a preparation for their advanced study, the ability to write a text coherently is very much needed. However, some language experts admit that it is not easy to be able to write well even though writing in their own native language. Brown (2004) states that only very few learn to express themselves clearly with logical, well-developed organization that accomplishes an intended purpose. Yet, we expect our students as foreign language learners to write a research report coherently with the right use of cohesive devices.

A question often comes up from the writer's mind why writing has become such a very difficult subject for most of the students; even English department students who have studied English for ten years or more still could not write a text cohesively or coherently. The fact that the texts they write are mostly incorrect, just like a list of ideas with no connection one to the other, the words, phrases being jumbled, non-cohesive or incoherent. Taufiqullah (2010) in the summary of his research conducted at Pancasakti University, Tegal, indicated that the students' writing competence was very poor in which their essays were not well organized, less mechanical aspects used, less of content materials about the topics, poor organization and improper use of grammatical aspects as well as unreadable sentences in their essays.

The students' inability to write well is assumed due to the complexity of the foreign language itself as in its grammar, vocabulary, and rhetorical conventions. This assumption is quite correct for the fact that the vocabulary and grammar in English are totally different from the vocabulary and grammar in Indonesian. That is why the difficulty in mastering these language components, grammar and vocabulary will of course contribute to the inability to write a text well. As cited by Kern (2000: 171) from the studies conducted by Bland, Noblitt, Armington and Gay (1990), the early learners of a new language were dominated by the difficulty in vocabulary; while the advanced learners as students in universities are dominated by the genres and rhetorical organization problems. Consequently, the text they write often does not show its unity or incoherent for they don't know much how to link 
one sentence to the other or one paragraph to the other cohesively.

This problem leads the writer to investigate whether or not the students' abstracts of their final project reports are coherent and cohesive. What is meant by coherent here is that the sentences or paragraphs in the text really connect one to the other and not just like a bundle of unconnected sentences which do not convey any ideas. In other words, all sentences in the text must be linked with the right use of cohesive ties such as conjunction words, substitution, reference and ellipsis in order to create coherence. In line with that idea, other experts also say that providing transitions between ideas like using transitional expressions, such as nevertheless, however, moreover, on the other, etc. and using pronoun reference or parallel form will make a text as a whole.

A text is considered incoherent when the words or sentences in each paragraph are not fitting together well. They are just like a list of points or ideas with no connection to each other, which result in readers' difficulty in following the writer's ideas. In this study therefore, the researcher would like to find out whether or not the undergraduate students of the English Department of PGRI University Semarang have written their abstracts in their final projects reports coherently and cohesively.

\section{LITERARY REVIEW}

\section{Abstract of the Final Project}

The ability to write a text is of a vital role and vital requirement for the university students since the prerequisite of the university graduation is the submission of their final project report as a product of a research. In spite of such an important role, based on the writer's survey, it has shown that many university students are not able to write even a simple article in English. The inability to write an English article with reasonable coherence and accuracy does not only happen to the Indonesian students but also to the native speakers of English as stated by Celce-Murcia (2001) that many of them never truly master this skill.

The fact that writing a final project report is not totally different from writing the other kinds of text as it is a means of communicating ideas to others or readers but a little bit difference can be noticed here in which in research report a writer begins with a thesis question which latter turns into a thesis statement (McMahan \& Day 1984). From this thesis statement the writer will be able to develop the paper into a number of pages in a clear and coherent way. The clarity and the coherence of the text depends very much on the writer's way in organizing and expressing his thought as stated by Kern (2000) that it is in the research writing a writer should be able to think explicitly about how to organize and express thoughts, feelings, and ideas in ways compatible with envisioned readers' expectation. In addition, research or academic writing has its feature as an engagement with other people's view in some way. It means that the content, the information and the organization of the text is relevant to the reader's knowledge and interest which accordingly renders the message intelligible.

Oshima and Houge (2006) support Kern's ideas in which they state that in academic writing, the writer should pay attention to the audience who will read the writing, the tone of the writing and the purpose of the writing. In general, the people who read the academic writing are the scholars, lecturers, students or researchers. Therefore, the tone of the writing is usually formal and serious. Formal means that academic writing is written objectively without being influenced by personal feeling and must be based on the investigated knowledge to reinforce the arguments. Johns (1997) noted that finding argument in a reading and noticing how data, examples, or narration are used to support this argument are essential academic abilities that are practiced by faculty from many disciplines.

Seow ( 2010) states that the process of writing comprises of four stages, namely planning, drafting, revising and editing but some other experts state six steps, among others are choosing a topic, gathering ideas, organizing, writing the text, reviewing the structure and content and revising the structure and content. By looking at the process of writing as stated above, it seems that in order to produce a good text one needs time and energy and why that happens? The answer is that writing is a complex skill in which the writer should make sure whether or not the topic, the structure and the content are appropriate. Whether or not the sentences in a paragraph are related one to the other or each paragraph follows logically on from the previous one and coherent, so all of them become a careful consideration for the writer to write a text or a final project report.

Abstract, as part of the final project report should also be written concisely, clearly and most importantly cohesively and coherently. According to Koopman (1997) abstracts that have become increasingly important as electronic publication data bases are the primary means of finding research reports in a certain subject area today. Therefore, the essential points or everything that is relevant to the knowledge of the potential readers should be included in the abstract as it is the summary of the whole paper.

In line with Koopman's idea, as quoted from the team of writing tutorial services of Indiana University, in http://www.indiana.edu/-wts/p.., it is stated that an abstract is a short, objective description of an intellectual resource, usually a written document with the purpose of allowing the readers to get the barebones information about 
document without requiring them to read the actual document. Since it is short and concise, it only consists of the objective of the study, methods, result and conclusion. In order that it can be understood well by the readers, the coherence, the logical relation of the text should be clearly established, besides its cohesion.

\section{Cohesion and Coherence}

The terms cohesion and coherence are interrelated that cannot be separated one to the other. Cohesion may refer to the ways in which sentences are connected by cohesive devices through which readers can perceive the semantic relationship between the sentences. While coherence is the unity of the text in which each sentence or each paragraph in the text hangs together to form a discourse that the readers can perceive its meaning. The unity of the text can be built through the use of cohesive devices that connect ideas from one sentence to the other or from one paragraph to the other. The cohesive devices which are often used to connect ideas in writing are among others: references, substitutions and ellipsis, conjunctions and lexical cohesion (Nunan, 1993).

Thus, with cohesive devices, a writer is able to show how parts of a text, sentences or paragraphs, relate to one another. In an academic writing, a writer cannot avoid using cohesive devices since text is built up around sentences and paragraphs and ideally they must be well connected so that it is logical and make sense. Thornbury (2005) supports the idea that a text needs to do more than simply hang together but making it make sense will make the text communicative and coherent. In line with Thornbury's idea, Yule (2009) also states that by itself, cohesion would not be sufficient to enable us to make sense of what we read. Many texts which are highly cohesive in which many connectors are employed to connect one sentence to the other but they are incoherent or difficult to be interpreted. Celce-Murcia and Olshtain (2007) suggest that planning ahead, organizing the ideas and propositions, providing connections and support, and constantly revising the text to make it more "reader-based" are some of the ways in which a writer creates coherence in a written text.

In conjunction with the study of the coherence of the text, Thornbury (2005) suggests two perspectives: the micro-level and macro-level coherence. At the micro-level, the text is considered coherent when the readers' expectation is met. It means that the meaning in sentences can easily be understood by the readers. How to detect the microlevel coherence of the text is firstly by looking at its logical relationships and secondly through the study of its theme and rheme or topic and comment. The study of coherence through its logical relationships means that the writer should be able to identify the logical relationships between its sentences, showing each sentence either anticipates the sentence that follows some element of the sentence that preceded it. While the study of coherence through theme and rheme means that to see what the sentences are about in the topic (theme) and what the writer or speaker wants to tell the readers about that topic is the comment (rheme). In addition, according to Halliday (1990) the theme is the element which serves as the point of departure of the message; which the clause is concerned. The remainder of the message, the part in which the theme developed, is called the rheme. As a message structure, therefore, a clause consists of a theme accompanied by a rheme, and the structure is expressed by the other whatever is chosen as the theme is put first. Meanwhile, at the macro-level coherence, texts achieve coherence because they are obviously about something, that is, there is an identifiable topic or topics.

\section{METHOD}

This research belongs to a qualitative one since the data are in the form of words, phrases or sentences. Three abstracts of the undergraduate students of the English Department of PGRI University Semarang were taken randomly to be analyzed their coherence and cohesion. Those abstracts were written by Student A (2014), Student B (2014) and Student C (2014). To analyze their coherence, the writer concerned on how the ideas presented and delivered to the readers in the texts. Therefore, the writer focused on the investigation of the coherence of the students' writing on their final project viewed from their logical relationship. There were some steps taken by the writer to analyze the text. At first, he broke up the paragraphs of the abstract into sentences; second, he analyzed each sentence using Theme Rheme analysis, and third, he analyzed their cohesion by looking at the cohesive devices used in connecting one sentence to the others

\section{FINDINGS AND DISCUSSION}

The Analysis of The Micro-Level Coherence, the Logical Relationship of the Sentences in the Text. Abstract 1 by Student A (2014)

Sentence (S)1: The aims of the study are (1) to find out the students's speaking ability before being taught using dance game, (2) to find out the students' speaking ability after being taught using dance game and (3) to find out whether or not there is significant difference of the students' speaking ability before and after being taught using dance game.

The theme (The aims of the study) echoes part of the rheme in the title (to improve students' speaking ability). It is followed by the rhemes (to find out). The phrase to find out is repeated 3 times to indicate the focus of the study. Ellipses are also 
used here in order to be more economical, for instance, point (1) ...before (the students are) being taught..., (2) (The aim of the study is) to find out ...after (the students are) being taught.... and (3) (The aim of the study is) to find out ... before (the students are being taught using dance game) and after (the students are) being...... In this case, ellipses are used in which several phrases in each clause were deleted. Parallelism is also used in these rhemes, for instance, the use of to find out....

S2: The sample of this study was 23 students.

The theme (the sample of this study) answers rheme1 (to find out...); this suggests that theme 2 is giving the answer of what technique is used in order to find out the students' speaking ability.

S3: The techniques which used in collecting data were oral test.

Though this sentence is ungrammatical, the theme tries to give the information of what to do with rheme/ comment 2 .

S4: The instrument which used in collecting data was speaking practice.

Again, this sentence which is ungrammatical which lacks of verb be was and the inappropriacy of using preposition in tries to give the answer of rheme 3 of what instrument was used for collecting the data.

S5: The components to measure are (grammar, vocabulary, comprehension, fluency and pronunciation).

There is no agreement between the subject, the component and verb be are. However, this theme is actually clarifying rheme 4 in which speaking may be assessed through its components of grammar, vocabulary, comprehension, fluency and pronunciation.

S6: From the data analysis, the writer got the mean of improvement speaking skill of the students for pre-test (the improvement of the students' speaking skill before the students being taught using dance game) was 57.17.

The researcher gives the summary of what he had done with the data collection but he misintepreted the data analyzed by mentioning the improvement of the students' speaking competence though treatment was not given yet. Besides, the verb to be in was 57.17 is redundant because the main verb of this sentence is got.

S7: It could be categorized into fair by referring to the table of the criteria of students' competence
This theme answers rheme 6. It in this theme refers to the average score 57.17

S8: The writer gave treatments before continued the post test.

This sentence seems to be separated from the previous one due to the lack of using cohesive ties. In this case, the researcher started to give a new information of treatment that will be further discussed. Besides, the use of the verb continued in this sentence is incorrect; it should be continuing for it is preceded by preposition before.

S9: The treatment was applying of dance game in teaching speaking.

The previous rheme becomes topic; treatment anticipates a description.

S10: Then the writer gave posttest.

The rheme post-test is carried over from theme 8 ; the researcher tries to affirm that post-test was done after the treatment.

S11: The writer got the mean of improvement speaking skill of the students for posttest (the improvement of the students's speaking skill after the students being taught using Dance Game) was 71.21

This theme is the same as theme 10; new rheme, mean score of 71.21 is given emphasis which anticipates for further commentary. However, the phrase improvement speaking skill is incorrect; it should be the improvement of speaking skill.

S12: It could be categorized into good by referring to the table of the criteria of the students' competence

The theme it refers to the previous rheme, rheme 11 , the score of 71.21 . It is coherent

S13: After that, the writer got the result of t-test

The cohesive device after that refers to the temporal, the continuation of analyzing the data using t-test.

S14: It was 3.36.

The theme it refers to the result of the t-test.

S15: So, there was significant difference of the students' speaking skill before and after being taught using Dance Game. 
Finally, as the expectation of the readers, a conclusion is given here that there was significant difference of the students' speaking skill before and after being taught using dance game. However, the researcher did not show the comparison of the t-test value and t-table before the conclusion. So, it is clumsy. It is not coherent.

S16: It could be seen from the result of t-test score that it was higher than t-table $(3.36>2.07)$.

The theme is carried over to give stress on the significant difference of the students' speaking skill by giving the comparison of the t-test value and ttable. Sentence 16 should appropriately be placed before sentence 15 .

S17: The writer suggest that the teacher can apply dance game as media in teaching speaking.

This sentence is carried over as a consequence of sentences 15 and 16 that being effective of using dance game media in teaching, the teacher is suggested to use this media.

S18: The teacher should give a chance to the students to perform their speaking ability.

The last sentence seems to have no connection with the previous ones since there is no reason why students should be given a chance to speak. It is totally incoherent.

\section{Abstract 2 by Student B (2014)}

S1: Direct and Indirect Speech is a material that is difficult to be leant because there are many rules about it, like the changes of tenses, verb, pronoun, and adverb of time.

The theme is (Direct and Indirect Speeech) and is followed by the $\operatorname{rheme}$ (a material that is difficult to be leant because there are many rules aboout it, like the changes of tenses, verb, pronoun, and adverb of time).This sentence tells the reasons why the writer chose direct and indirect speech as the title of her research and it is worth investigating since it is difficult to learn. The reference (It) in this sentence refers to the phrase of direct and indirect speech and it is properly used since the word speech is singular. There are several spelling mistakes in terms of writing vocabulary, like (leant), speeech) and (aboout) that should be (learnt), (speech) and (about). It indicates that the writer is very careless.

S2: In this research, the researcher is interested in analyzing direct and indirect speech on news item found in Jakarta post daily newspaper

The theme is the same as theme 1. It is coherent since it is related to the previous sentence.
The phrase direct and indirect speech is repeated to show the writer's interest to analyze it.

S3: By using newspaper, the learner will be interested to study about direct and indirect speech.

The writer used the phrase (By using newspaper) is intended to relate sentence 2 but the theme (the learner) does not have any connection with the previous sentence. So, it is not coherent

S4: This final project is to describe how the direct and indirect speech realized in news item text in Jakarta Post, to know the dominant type of direct and indirect speech found in news item text in Jakarta Post.

The theme (This final project) is used as the synonym of (this research) in sentence 2 followed by the news of what the student is going to do with the direct and indirect object and she further states that she wants to learn the types of direct and indirect speech which are dominant in Jakarta post newspaper. Though this sentence shows its logical relation with the previous one, the coherence is obscure.

S5: In this research, the researcher applied descriptive qualitative research

Again, the phrase (In this research) is used interchangebly with the phrase (This final project). In this case, she wanted to show its connection with the previous sentence and the theme (the researcher) gives the information of what kind of research employed in doing the research. Its logical relation is quite clear but not smooth.

S6: The object of the study was the direct and indirect speeech found in news item text on Jakarta Post.

The theme (The object of the study) is giving the answer of rheme 2 where the researcher wants to analyze the direct and indirect speech. The phrase direct and indirect is unnecessarily mentioned repeatedly that does not mean anything. The reseacher is so careless that she often writes the word speech incorrectly.

S7: The researcher focused on direct and indirect speech text entitled: "Ukraine feels nervous as big powers debate fate, Australian ship detects new signals as plane hunt narrows, Australian navy ship detects new dignals 'consistent' with black boxes, bali is reaching saturation as tourist hub, 48 drug smugglers busyed at Soekarno-Hatta International Airport."

Rheme 7 ("focused on .......") is the same as rheme 2, 4 and 6 where the researcher tries to stress 
the specification and the the title being studied. This sentence is ungrammatical for there is no plural marker to show the texts being studied.

S8: From the explanations above, the researcher found that "said" is the dominat main verb applied both in direct $(63.33 \%)$ or indirect speech $(82.14 \%)$.

This sentence gives the conclusion of what the researcher had done with the data. Without explaining how the data were analyzed she directly gave the information that "said" was the dominant main verb applied both in direct $63.33 \%$ and in indirect speech $82.14 \%$.

S9: "Simple present tense" is often used in direct speech $(40 \%)$, while "simple past tense" is often found in indirect speech $(78.57 \%)$ in that news item text.

As the continuation of sentence 8, the researcher tries to give the information of the use of simple present tense $40 \%$ and simple past $78.57 \%$.

S10: Based on the findings, the dominant type used in direct and indirect speech is direct statement $(51.72 \%)$.

This sentence echoes further answer of rheme 4 (the dominant type of direct and indirect speech). It suggests that direct statement $(51.72 \%)$ was used in direct and indirect speech.

S11: The researcher suggest that the teacher should use newspaper as an additional reference in teaching English

As a consequence of sentences 8,9 and 10 , the researcher suggested to use newspaper as the media of teaching English as a foreign language.

S12. By using newspaper, the learners can increase their understanding in learning English.

Finally, the researcher tries to state the implication of the research findings but it doesn't make sense since the findings are mainly about the dominant types of direct and indirect speech used in Jakarta Post newspaper not the importance of using news paper in learning English.

\section{Abstract 3. By Student C (2014)}

S1:The objective of this final project are: 1) To find out the students' reading comprehension of decriptive texts taught using discovery learning method. 2) To find out the students' reading comprehension of decriptive texts taught without using discovery learning method., 3) To find out whether or not there is a significant difference on the mastery on reading comprehension of descriptive text between the students taught using discovery learning method and those taught without discovery learning method of the seventh grade students of SMP 3 Pati in academic year 2013/2014.

The theme (The objective of....) echoes part of the rheme in the title (to Improve Students' Reading.... ). It is followed by rheme1 (To find out .......), rheme 2 (To find out ........) and rheme 3 ( To find out whether or not ......... ) as the beginning of the answers of the theme of the title. Parallelism, and ellipses are used in this sentence.

S2: In doing the reseach, the reseacher conducted true experimental design.

The rheme ( true experimental research) answers rheme 1, 2, and 3 (to find out); it gives the information of the design used in order to find out the students' competence in reading comprehension. The words research and researcher in sentence 2 have wrong spelling. It shows that the student's accuracy is very poor.

S3:Both groups are administrated both a pretest and a post test, but the treatment is only to the experimental group.

This ungrammatical sentence does not make sense due to the incorrect choice of diction like administrated both a pretest and a posttest. The word groups hasn't been mentioned before, so it is improper to mention both groups in this sentence. Likewise, the word administrated does not fit with the context.

S4: Pre-test was given before treatment and after treatment was done the student were given post test

This sentence explains about the steps in doing the research as required in rheme 3 .

S5: The value of $t$-count $=3.329$ and then it is consulted to the t-table at the level of significance $5 \%$ equal to 1.684 .

This sentence gives information on what the writer had found in her research. The theme (the value of $t$-count) is a refocusing of rheme 3 of theme 1(To find out whether or not there is a significant difference on the mastery on reading comprehension of descriptive .....) and the value of 3.329 is the answer or finding.

S6: It means that $t$-count is higher that $t$-table (3.329>1.684).

The reference it in this sentence refers to the previous sentence, the value of the t-count clarifying that 3.329 is higher than1.684. It is coherent 
S7: It shows that Ho is refused and Ha is accepted.

The reference it in this sentence refers to the comparison of the t-count and t-table. This concluding remark is coherent.

S8: So the conclusion is that using Discovery Learning can improve the students comprehension in reading descriptive text, it is more effective that without using discovery learning method.

This sentence is started with using a causal way or with a cohesive tie (so) to indicate an inference or conclusion that using Discovery Learning can improve the students' reading comprehension of a descriptive text by showing the comparison of the t-count and t-table. So, it is coherent.

S9: The writer suggests the English teachers to hold a good learning teaching process and hopefully it will make the students interested in learning.

The theme (The writer) is refocusing the necessity of the Discovery Learning while the rheme is the suggestion of implementing the technique of teaching.

S10: It can be used for their method to teach the students and to train them in improving their reading comprehension of descriptive texts.

The theme (it) refers to the Discovery Learning and it suggests further on the use of discovery learning in teaching learning process.

S11: So it can motivate the students and simulate them to be communicative in learning English.

The cohesive tie (so) refers to a causal way as a concluding remark and the reference (it) refers to the Discovery Learning. The rheme (can motivate the students...) is new information of the advantage of using Discovery Learning that can stimulate the students to communicate.

\section{The Cohesion of the Texts}

If we observe the way how the students write their abstracts, three of them used the following cohesive devices:

a. Lexical cohesion is realized in lexical repetition like the phrase to find out...(sentence 1 text 1 and sentence 1 text 3). It is used to emphasize its significance in the entire text. While the synonyms, antonyms, substitutions are not used.

b. Grammatical cohesion is realized in

1) reference: it (abstract 1 in sentence 7 , 12, 14, 16; abstract 2 in sentence 1 ; abstract 3 in sentence $1,5,6,7,10$ and 10).

2) Substitution of clause element: so (abstract1 in sentence 15; abstract 3 in sentence 8, 11)

3) Ellipsis realized in (abstract 1, sentence 1; abstract 3 sentence 1)

4) Conjunctions: coordinating and subcoordinating conjunctions realized in and, but, so, after, before ( Abstract 1 sentence 1, 11, 13, 15; abstract 2 in sentence $1,3,4,7,8$; abstract 3 in sentence 3, 8, 9 and 10).

5) Comparatives realized in higher (abstract 1 in sentence 16; abstract 3 in sentence 6)

\section{DISCUSSION}

Overall, if we observe the three abstracts mentioned above, without regarding their grammatical accuracy, their logical relationship cannot clearly be identified. Just, for instance, text 1 sentence 7, the pronoun it refers to rheme mean in sentences 6 . But sentence 7 does not cohere with sentence 8 for it discusses the treatment while sentence 7 discusses the mean. So, there is no logical relationship between sentence 7 and 8 . Likewise, sentences 8 and 9 in text 3 do not show their relation since the two sentences discuss different rhemes. Sentence 8 discusses discovery learning while sentence 9 discusses a good learning teaching process. The student used pronoun it as the conclusion but the pronoun it does not refer to the referent discovery learning. It refers to a good learning teaching process. The last sentence in sentence 11 in text 3 , the pronoun it is still obscure whether it refers to $a$ learning teaching process or discovery learning since there is no signal of semantic relation.

In text 2, the student tried to relate each sentence to the other with some words repetition; for example, the phrase direct and indirect speech in sentence 1 is repeated many times in sentence 2,3 , $4,6,7$ and 10 to form chains of the running text. It is a little bit more coherent any way compared to the other two abstracts for its logical relation is quite apparent. By using word repetition the student wants to carry and advance the theme of discourse. However, she did not use sentence adverbials as signals of semantic relation. Therefore, the unity of the text seems to be clumsy or does not run smoothly. The unavailability of the sentence adverbials in the abstracts may be due to the limited knowledge of the students on how to apply them in order to relate ideas or to reinforce earlier ideas. The following sentence adverbials are very important to be used in writing academic paper. For instance, however, nevertheless, on the other hand, after all are used to relate ideas cohesively; furthermore, moreover, in addition etc. are used to reinforce 
earlier ideas; therefore, consequently, hence are used to relate ideas casually; likewise, similarly are used to relate ideas equally; for example, for instance, namely are used to expand earlier ideas etc. However, such sentence adverbials are rarely used by the students in writing their abstracts and consequently, the logical relation is not quite apparent.

Besides, the students also show their incapability of writing texts with the correct grammar for there are so many grammatical or spelling mistakes found in text 1 , text 2 and text 3 . For instance, the grammatical mistakes in text 1 , sentence 1: possessive (students's), should be (students'); sentence 3,passive voice (The technique which used ....) should be (the technique which was used...); sentence 4,passive voice (The instrument which used...) should be (the instrument which was used...); sentence 5,plural form and passive voice (The component to measure are ....) should be (the components to be measured); sentence 8 , preceded by preposition (...before continued ...) should be (before continuing); sentence 17,present verb (The writer suggest...) should be (the writer suggests....). While the spelling mistakes can be found in text 2, sentence 1:leant for learnt, speeech for speech, aboout for about; text 3, sentence 1: to findout for to find out; sentence 2 reseach for research, reseacher for researcher.

\section{CONCLUSIONS AND RECOMMENDATION}

The result of the study shows that many of the students still find difficulties in writing abstract coherently. Most of them seem to have insufficient knowledge on the use of cohesive devices or sentence adverbials that can relate ideas stated in the earlier sentences or reinforce the ideas. Most of the abstracts are not well-formed in which the sentences are not hanged together that make the texts coherent nor make sense. The fact that sentence adverbials like however, nevertheless, yet, furthermore, moreover, in addition which are quite important to relate ideas cohesively are not used in the texts. However, the students have tried to link their sentences in the texts in a number ways like using lexical cohesion and grammatical cohesion though they fail to meet the readers' expectation.

It is therefore, recommended that the lecturers, particularly those who teach academic writing should enhance the students' academic writing competence through having a lot of practices in writing. Besides, they should also explain the cohesive devices or sentence adverbials with some examples that will help them learn how to apply the cohesive devices in connecting one sentence to the other or from one paragraph to the other in order to form the unity of the text.

It is also important to note that the students still have difficulties in constructing passive and active sentences. Besides, they also have difficulties in mastering the plural forms and gerund as there are some mistakes found in text 1 sentence 5, 8 and text 3 , sentence 1 . These kinds of grammatical mistakes influence the message conveyed in the text that could possibly arouse misunderstanding. Hence, enhancing the students' grammar mastery is also of primary importance for enabling the students to write academic paper well.

\section{REFERENCES}

Bland, S.K., Noblitt, J.S., Armington, S., \& Gay, G. 1990. The naive lexical hypothesis: Evidence from computer assisted language learning. Modern Language Journal 7(4), pp. 440-450.

Celce-Murcia, M. (2001). Teaching English as a second or foreign language. London: HeinleHeinle

Celce-Murcia, M. and Olshtain, E. (2007). Discourse and context in language teaching: A guide for language teachers. Cambridge: Cambridge University Press

Dian, S. (2014). The Effectiveness of Discovery Learning Method in Curriculum 2013 to Improve Reading Descriptive Text for Seventh Grade Students of SMPN 3 Pati in Academic Year 2013/2014. Final Project

Halliday, M.A.K. (1990). An introduction to functional grammar. New York: St Edmundsbury Press Ltd

Johns, A. M. (1997). Text, role, and context: Developing academic literacies. Cambridge: Cambridge University Press

Kartika, D. S. (2014). An analysis on direct and indirect speech on news item text on daily newspaper of Jakarta Post. Final Project

Kern, R. (2000). Literacy and language teaching. Oxford: Oxford University Press

Koopman, P. (1997). How to write an abstract. At http://www.ece.cmu.edu/koopman/essays/abstract.html.

McMahan, E. and Day, S. (1984). The writer's rhetoric and handbook. New York: McGrawHill

Mutaqin, D. (2014). The use of dance game to improve students' speaking ability: A case of the tenth grade students' of SMA Walisongo Semarang in the academic year 2013/2014. Final Project.

Nunan, D. (1993). Introducing discourse analysis. London: Penguin Books Ltd.

Olshtain, E. (2001). Functional tasks for mastering the mechanics of writing and going just beyond. In M. Celce-Murcia (Ed.), Teaching English as a Second or Foreign Language (pp. 207-217). Boston: Heinle \& Heinle.

Oshima, A. \& Hogue, A. (2006). Writing academic english. California: Addison Wesley Publishing Company 
Seow, A. (2010). The writing process and process writing. In J. C. Richards and W. A. Renandya (Ed.) Methodology in Language Teaching: An Anthology of Current Practice (pp. 315-320). New York: Cambridge University Press

Taufiqullah. (2010). Improving students' ability to classroom action research to the third semester students of English department, write essays through self-assessment: A faculty of teacher training and education of
Pancasakti University in the academic year 2009/2010. Diponegoro University, Semarang: Unpublished Thesis

Thornbury, Scott. (2005). Beyond the sentence: Introducing discourse analysis. Oxford: Macmillan Publishers Limited

Yule, George. (2009). The study of language. Cambridge: Cambridge University Press

Writing tutorial services of Indiana University in http://www.indiana.edu/-wts/p. 